\title{
Research on the Situation of General Education Mode in Colleges and Universities of China
}

\author{
Qing SUN \\ Air Force Engineering University \\ Xi'an, China \\ sunqing2002@126.com
}

\author{
Yutong ZHANG \\ Air Force Engineering University \\ Xi'an, China \\ 77496794@qq.comAuthors
}

\begin{abstract}
As a guiding concept, general education has been introduced and widely spread in colleges and universities of China in recent decades. However, combined with the current situation of higher education in our country, many problems have to been solved urgently so as to establish a healthy, complete and harmony education system. This issue mainly analyzes the developing situation of general education in colleges and universities of China, and also discusses the shortages from various aspects, and even supplies the improvement suggestions.
\end{abstract}

Keywords-educational system; education mode; general education; Personnel training

\section{INTRODUCTION}

After human history entered the third millennium, an important trend in the Second World War II accounted for the mainstream trend of world history "globalization" to accelerate the development of the 21 century history, such as the development of science and technology, the formation process of knowledge economy, and the dialogue among civilizations, and all the above are associated with globalization, meanwhile, they directly impact the transformation of the university idea and university education.

General education in Chinese comes from general education in American and also absorbs the ideology of liberal education in ancient Greece. The concept of General education had been accepted by Chinese just until 1980s and has been widespread after that.

According to the situation of colleges and universities in china, the talent training mode of undergraduate education is to form the structure of knowledge, ability and quality and the style to establish which. In fundamental, it has formulated the talent feathers and expresses the idea and educational concept. Article 16 of Higher education law specifies stratified training objective, and the undergraduate education of which is to train students systematic master the fundamental theories and knowledge of one subject and the basic skills, measures and related information of one profession, so as to process preliminary ability of going in for actual work and research. However, the training objective of colleges with different level and type are not the same, in any case, all of which should be focused on social requirements based on the same foundation.

In the new era of twenty-first Century, the tendency of globalization has catalyzed the effects of nationalization and territory. Under the impact of globalization, the first new challenge faced by the university is that how does the local culture contend with the strong hegemony. The new challenge to university in the surge of globalization and localization the retreat lost, stretched. College education because of the knowledge era and must be adjusted.

\section{ANALYSIS TO THE CONCEPT OF GENERAL EDUCATION}

\section{A. The concept of general education}

General education is a historical and geographical concept with rich intensions and multi level. Combined with the actual condition of China, we can analyze it from the three aspects of educational idea, education concept and talent training mode.

\section{1) Educational idea}

General education is a kind of educational idea, which has been widely accepted by large amount of educational researchers. The idea is not a patent only for university or a certain kind of schools but for all. We emphasize the general education in universities for it has more particularly important significance. We pay more attention to general education to solve the problem that over specialization and professionalization will lead to narrow knowledge, limited vision and biased thinking. Meanwhile, professionalism is a salient feature of higher education. However, general education continues to face challenges from the rapid development of professional education and vocational education. Based on this, practice and research in general education has been developed by different countries, regions and universities with different types and levels.

In a sense, as a people-oriented education mode, general education emphasize sound person training but not regarding human as object or tools.

\section{2) Education concept}

In board sense, general education includes all but professional education. In general, it mainly includes the course to realize its target in undergraduate training program, and the narrow content just includes the course named general education, which contains completely the basic content of humanity, society and natural science, such as language, mathematics, literature and art, historical culture, moral reflection, science and technology and so on. More personality shaping, thinking training and method mastering should be emphasized in teaching. We know that it is the base of 
professional course study, and is also the foundation of being a sound person to adapt to social development.

\section{3) Talent training mode}

As a talent training mode, general education can be understood corresponding to professional education mode. From the aspect of education content, content of general education and of professional education are both included and constitute the whole of the university education and are complement each other. However, as two kind of talent training modes, great difference such as educational idea, system of education, content and teaching methods exist between them.

China universities and colleges have learned establishing the talent training mode of special education from Former Soviet Union since 1952, and large amount of work have been done to design educational idea, course system, teaching content, teaching methods, training system, operating mechanism and organizational institution. On the surface, general education is operated by offering some general courses and educational activities, however, further developing will relate the reform of talent training mode and even the university system.

From the three aspects to understand general education, we can give out some explanation as follows.

At the ideal level we can see that general education is appropriate for all persons and all schools because being a perfect person in the goal of every person's life. However, from the content perspective, different operating mode, measures and extent of general education have been adopted in universities with different levels and types. In some elite universities, large amount of general education courses have been offered in about two years, and the professional education is offered in postgraduate stage. However, in vocational colleges, several general education courses are offered and they ignore that more attention should be paid to train students learn how to think and solve problems comprehensively and perfectly, but not be a "robot". At the mode level, general education mode in different universities act its own characteristic and it need not to be measured by a same standard.

Being a part of university education, general education should obey and serve the overall goal of talent training, and even accomplish the inner spirit and characteristic of its own.

In China, the goal of general education can be defined as training sound people, and it is healthy personality education. Requests from two aspects should be included in the specific criteria. For one thing, general education should devote to train the fundamental knowledge, ability and morality to be a person, for another, as a member of the society, one should be rich of the sense of social responsibility. Meanwhile, one should gain a special skill to enable itself to find its feet in a crowd.

\section{B. The spirit of general education should be fully developed in Education.}

General education materials may be similar to other major textbooks, but the learning and teaching model and objectives will be different, mainly reflected in the following aspects.

1) The value of general education is not only rich selfexistence, but also to expand the achievements of human civilization. The spirit of the times in general education is to attach importance to students' ability to criticize and analyze and think. Students continue to self-reflection, questioning both assumptions, creatively solve the problem, enhance the surrounding environment concerns, to influence the future participation of important historical period to form a key ability.

2) General education is a preparation for the future life of education. The courses offered by the university are not designed to develop students' knowledge, skills and mental abilities, but to develop critical skills to guide life after graduation, and to master the tools of understanding and reflection in the face of future world challenges.

3) General education is a useful education. This does not mean that it is aimed at professional training, but to provide guidance for the direction of life after college.

4) General education is not by meeting the students familiar with things and existing ideas to enhance students' self-confidence. Instead, it challenges their existing assumptions, turns familiarity into unfamiliarity, and lets students lose direction and then reorient to understand the truth behind things.

5) The completion of the goal of general education is to challenge the existing assumptions and emphasize selfreflection, in order to develop students critical and analytical thinking ability, and have explored the extreme historical moments and unprecedented phenomenon, so that students contact and fully understood Heterogeneous point of view.

6) General education is the life must have. This kind of education is not taught by professional institutions, most postgraduate courses do not teach the content.

In short, to cultivate a student with a sound personality and academic capacity, professional content is not enough, the school should give students on the social and overall cultural content of the curriculum so that students can learn in the accumulation of their own professional Quality, on the one hand to cultivate physical and mental, to achieve sound development goals.

\section{ANALYSIS TO THE DEVELOPING SITUATION OF GENERAL EDUCATION IN CHINA}

With the introduction of idea and the attention from domestic scholars, general education has been widely spread in the field of higher education and extended to general colleges. Nowadays, it's fruitful either from theory to practice. 
Meanwhile, many problems have been exposed. For example, required courses of general education in universities emphasize more on the function of political education, tool skill mastery and the basic education of natural science, which has not embodied the spirit of general education. In fact, colleges should establish the system of public compulsory course based on the teaching idea and target and regard which as a part of general education.

\section{A. Elective course of general education is lack of clear objectives.}

The training target of general education is to produce qualified citizens and sound persons satisfied with the requirement of modern society, and to train college students with elegant taste and perfect personality structure. Unfortunately, two misunderstandings exist in our training goal. One is that general education has been understood as culture quality education or non-major quality education beyond the professional one. From the curriculum setting we can see that beside professional courses, many are offered such as culture, history, philosophy and art of natural science, and the function of broaden the knowledge is emphasized while the unique advantages of broadening one's horizon and heart, training good moral character and elegant taste are ignored, which makes general education remain in a lower level. The other misunderstanding is that in order to improve the employment ability, many foundation courses have been reduced in the name of general education, which will directly lead to the target with intellectual, cognitive and lacking of emotionality, experience and personality. So, powerful theoretical support and guidance are needed urgently to establish the development of general education.

\section{B. Teachers and students pay not enough attention to general education.}

Facts show that general education is even to be regard as a burden to finish credits. They choose general education course arbitrarily and passively, and many even consider it as entertainment. With no provision, participation and consolidation, it's really hard to achieve anticipate result.

In colleges, teachers are encouraged to establish general education course. However, with heavy tasks of professional teaching and scientific research works, even for the reason that serious tendency of paying more attention on research and less on teaching exists in the present evaluation system and appointment system of teachers, many excellent teachers emphasize on professional course or have no time on general education course.

\section{The course structure of general education is unreasonable and the quantity is less.}

Restricted by the serious shortage of teachers, the rule of establishing course is processed not according to course but to teachers. Questions of miscellaneous content, disorder structure and too wide range are widespread. Meanwhile, the setting up of general course is random, and short of the guides of unify course theory. Some courses come from professional ones with little change and the contents are over specialism. The elective course of general education can't do better than professional one in usefulness and than required one in mandatory, which makes it be hard to be valued by teachers and students. In addition, the course is often squeezed by others and is set too few credits.

\section{The teaching content and method need to be improved.}

From the class scale we can see that generally, the elective courses of general education are often adopted the style of a group class with 80 to 200 students. The big number of students attending lectures is unsuited to the teachers organizing statement and discussion, which leads to the teaching to be processed unilaterally, and the class becomes the teacher's position, meanwhile, it is difficult for the students to gain the right of speech. From the teaching method, some universities have successfully carried out the mixed teaching model to general education course. With their own characteristics, teachers bold innovation in teaching methods and some even adapt various forms to increase the attractiveness of the course such as experimental class, speech contest, network teaching platform, site visiting and explaining, photo exhibition, appreciation of classic video and so on. As a whole, students say high praise to the teachers. Unfortunately, some courses stay on the level of knowledge teaching and ignore the requirement of the methods and approaches to acquire knowledge. On the scale of teaching contents, the types of elective course are mainly focus on outline, common sense, practical and leisure and pay little attention on comprehensive or interdisciplinary. In fact, fewer subjects are set to reacting the latest developments in science and technology, scientific frontier knowledge and latest achievements in science and technology, some courses are too professional and hard to gain the general education target of popularization, and some are old, which can't satisfy the students' interesting and growing demand.

\section{THE DEEPENING OF UNIVERSITY GENERAL EDUCATION}

As has been analyzed above, being the 21 st century intellectuals to establish a place, the University is indeed necessary to enhance the quality of life science students.

There are also a small number of colleges and universities in the course of excellent quality, profound content, but at this stage to see the end of the introductory courses to taste the majority, and even there are many entertainment-oriented socalled "Basic curriculum" and "general curriculum, wind flow and" students think that "basic or general curriculum is nutrition credits" the wrong impression. Once this false impression is formed, the excellent teaching and research teachers in the university will see the foundation and general education courses as a way out, so that serious students will find it harder to find good general education courses. Therefore, general education must strive to deepen.

\section{A. The concept of deepening.}

Return to their own, the so-called "deepening" should not be misinterpreted as the professionalization of the basic and general knowledge curriculum, teaching more professional knowledge and making it a leading course for the advanced professional courses. 


\section{B. The deeping strategy}

1) Combination of knowledge and practice

The relationship between "knowledge" and "behavior" is one of the fundamental subjects of Chinese thought and educational tradition for thousands of years. Only when the "knowledge" learned in the curriculum is put into practice can the academic research of modern universities be divorced from human life. In modern universities, the pursuit of knowledge in modern universities has become a kind of objective activity of seeking out science and management, and the so-called "Wanwusangzhi" of the ancients has become a kind of objective activity that has nothing to do with human life. Not far from. As a result, the variety of knowledge taught in the university classroom is integrated with the learner's life or life experience.

\section{2) Combination of thinking and teaching}

The combination of the two will make teaching is no longer a memory of the standardization of knowledge indoctrination and imparting, but through the teaching activities to enhance students critical thinking ability. The university general education curriculum must be thoughtoriented, in order to enhance the depth of the course, lay the foundation for students' future lifelong learning.

\section{The deepening method}

We can use lecture courses to promote the concentration of the school part of the human and material resources to the way the group teaching, a particular topic closely, the development of a high degree of knowledge bearing lecture courses to deepen the content of general education and basic education. You can also read the original way, experience the originality and inspire students of originality and thinking.

\section{CONCLUSION}

Aiming at the weak link in the general education of our universities and colleges, many theoretical and practical problems are needed to be further untangled. For example, we should pay more attention on establishing the undergraduate education system of general education mixed with the professional one; and we can improve the course quality totally by adhering to the comprehensive development and personality development, meanwhile, overall planning is needed between the general education and the professional to strengthen the top-level design. In the next work, we can carry forward the professional characteristics and optimize the core courses to increase the course challenge. The improvement on elasticity and flexibility of the training program and the autonomy and selectivity to the study of students will effectively promote the students' values and sublimation, and it will also enhance the understanding of the traditional culture of excellence and of the human civilization. The sound development of general education will play a huge role in cultivating students' integrity and independence, in developing the critical spirit of science and the spirit of innovation, and in strengthening the practical and the entrepreneurial ability.

\section{REFERENCES}

[1] HUANG Junjie. University general education in the age of globalization. Peking University Press, 2006.

[2] GAO Hui,YU Xinrong. The meaning and the way to strengthen the traditional culture education: As the center in general education in colleges and universities. The Journal of Shandong Agricultural Engineering College.Vol.33.7,2016.

[3] XIE Debo, Global Models and China's Choice for Professional Education analysis and Expansion of Fundamental Pro Higher positions on Education, Fudan Education Forum, Vol.0.4,2016.

[4] YUKai.Survey and Analysis of General Education in Chinese Universiti es. Modern University Education, Vol.1,2003.

[5] WANG Qi, LIU Jiang-tao, LI Rui . Investigation and Analysis of General Education Development in Local Universities-A Case Study of Six Local Universities in Hubei Province. Journal of Shaanxi Institute of Education,Vol.32(5),2016.

[6] GONG Jinping. The Current Situation and Reflection on the Implementation of General Education in Chinese Universitie. Heihe Journal,Vol.3, 2011. 